\title{
Postmodern Tüketim Kültürü ve Kutsallık Biçimleri Üzerine Metateorik ve Kavramsal Bir Tartışma: Deneyim, Yaşam Tarzı ve Bireysellik Alanı Olarak Spirituiellik
}

\author{
A Metatheoretical and Conceptual Discussion on Postmodern Consumption Culture and \\ Forms of Sacredness: Spirituality as Experience, Lifestyle and Field of Individuality
}

Feride AYDEMIR*

Öz

Alternatif deneyimler, arayışlar öneren tüketim kültürü içerisinde spiritüel anlam ve pratikler de “özgün” ve "egzotik" deneyim alanları, yaşam tarzı alanları olarak karşımıza çıkabilmekte, bu süreç tüketim kültürünün çağdaşgörünümlerini sorunsallaştırabilmek açısından önemli kavramsallıklar sunabilmektedir. Spritüelliğin bireyselliğin dışa vurulduğu bir alana dönüştüğünü iddia edebileceğimiz bu süreç, postmodern tüketim kavramsallaştırmaları, New Age kültürü, bireyselleşme, ekonomik yapı, gündelik hayata dair fantezi ve arayışlar gibi dinamikler eşliğinde okunduğunda daha da anlaşılır hale gelmektedir. Bu çalışma, bu sürecin dinamiklerine ve güncel görünümlerine dair kavramsal bir tartışma yürütmeyi ve metateorik bir yöntem izlemeyi amaçlamaktadır. Çalışma bu tartışmayı üç düzlemde sürdürmeyi hedeflemektedir: a) Bireyselliğin sergilendiği bir alan olarak kutsallık; b) Spiritüel sembol ve anlamların kültürel tüketimi ve yeniden üretimi; c) Kutsal, spiritüel anlam, sembol ve pratiklerin meta-nesne olarak tüketim piyasasında yerini alışı. Bu çalışma çağdaş tüketim kültüründe spiritüel anlam ve içeriklerin bireysel bir mitoloji kurmanın, ayırt edici bir üslup ve tarz yaratmanın popüler ruhsal biçimleri haline gelebildiğini, kutsalın bugünün arayış ve fantezilerine denk düşecek şekilde yeni bir bakış ve öznel yorum etrafında yeniden yorumlanabileceğini iddia etmektedir. Kendini “mükemmel” hissetmenin, bedensel ve ruhsal bir "bilgeliğin” yol ve yöntemlerini sunan postmodern kutsallık biçimleri bireyselleştirilmiş bir hayat tarzı anlatısına spiritüel bir boyut katmakta, öte yandan metasal bir dolaşımla tüketim piyasalarında nesneleşebilmektedir.

Anahtar Kelimeler: Postmodernite, Tüketim Kültürü, Bireysellik, Postmodern Spiritüellikler, Maneviyat Tüketimi.

Arş. Gör., Ankara Üniversitesi, Halkla İlişkiler ve Tanıtım Bölümü, Ankara, Türkiye, E-posta: ferideguner59@gmail.com 


\begin{abstract}
Spiritual meanings and practices within the consumption culture that propose alternative experiences and quests can be seen as "original" and "exotic" areas of experience and lifestyle, and this process can present important conceptions in terms of problematizing contemporary aspects of consumption culture. This process, which we can argue that spirituality has turned into an area where individuality is expressed, becomes more comprehensible when it is read in the context of dynamics such as postmodern consumption conceptualizations, New Age culture, individualization, economic structure, fantasy and quests about daily life. This study aims to conduct a conceptual discussion about the dynamics and current aspects of this process and to follow a metatheoretical method. The study aims to continue this discussion on three levels: a) Holiness as an area of individuality; b) cultural consumption and reproduction of spiritual symbols and meanings; c) The place of sacred, spiritual meaning, symbols and practices in the consumer market as a commodity-object. This paper argues that in contemporary consumer culture, spiritual meanings and contents can become popular spiritual forms of individual mythology, of creating a distinctive style and that the sacred can be reinterpreted around a new look and subjective interpretation that corresponds to today's quests and fantasies. The postmodern forms of holiness that offer the ways and methods of feeling "perfect", and of a physical and spiritual "wisdom" add a spiritual dimension to an individualized narrative of a lifestyle, and on the other hand can be objectified in the consumer markets through a commodity circulation.
\end{abstract}

Keywords: Postmodernity, Consumption Culture, Individuality, Postmodern Spiritualities, Spirituality Consumption.

\title{
Giriş
}

Sadece rasyonel faydaya dayalı bir düzlemi değil, fantezi, imgelem haz ve arzu dünyasını da içerisine alan, bu anlamda gündelik hayat içerisinde kültürel bir işleve sahip olan tüketim olgusu çağdaş kültürü karakterize eden önemli dinamiklerden biridir. Tüketim maddi olduğu kadar simgesel de bir süreçtir (Featherstone, 2013, s. 210-211). Öte yandan gösterge ve sembollerin dâhil olduğu toplumsal ve kültürel bir süreç olarak da tüketim alanı (Bocock, 1997, s. 13) hem yeni söylem, üslup ve öznellik biçimleri yaratmakta, hem de kültürel ve toplumsal yaşamın çeşitli alanlarına yayılarak yeni eklemlenme tarzları ortaya koymaktadır. Kişiselliği sergileme, tarz ve beğenileri anlatımsal bir koda çevirme hem toplumsal kimlikler hem de toplumsal ayrımlar yaratma açısından merkezi bir fenomen (Bauman ve Lyon, 2013, s. 120) olarak tüketim, çağdaş kültürde tatmin olmaktan çok arzunun bitimsizliği, durağanlıktan çok heyecan, bulmaktan çok aramak üzerine kurulu (Bauman, 2012, s. 87) öte yandan bireyin akışkanlığını ve farklı kanallarda hareket edebilme yetisini de talep eden bir alandir.

Arzu stratejileri ile varoluşun maddi yanını kuşatan tüketim nesneleri kimlik, statü, farklılık kodları sunarak nesneyle olan ilişkiyi ihtiyaç ilişkisinden göstergesel ve simgesel ilişki bağlamında yeniden düzenlemektedir (Baudrillard, 2016, s. 101). Tüketim kültüründe sadece nesneler bir değiş

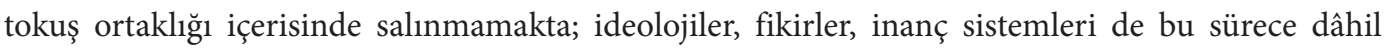
olmaktadır (Baudrillard, 2016, s. 111). Bu anlamda tüketim kültürü içerisinde spiritüel, dini anlam, sembol ve pratiklerin yeniden icat edilme, kullanılma ve dolaşıma girme biçimlerine odaklanmak tüketim kültürünün güncel karakterini anlamak açısından önemlidir (Featherstone, 2013, s. 211). 
Özellikle 1970'li yıllardan sonra hem dünyada hem de Türkiye'de dini ve spiritüel söylem ve pratikler hem politik hem de kültürel ve toplumsal bir tepki olarak geri dönmekte, kamusal alanın, popüler kültürün ve medyanın periferisinden merkezine doğru bir seyirle ilerlemektedir. Son yıllarda New Age akımları-ruhsallığı altında da toplanabilecek dini pratik ve söylemler tüketim kültürünün çeşitli kanallarında birtakım eklemlenme biçimleri meydana getirmekte, bu süreç dinsel ve profan arasındaki ayrımların silikleştiği bir etkileşimi ve kutsalın tüketim kanallarında metalaşmasını kapsamaktadır.

$\mathrm{Bu}$ süreçte popüler kültürün dini anlam ve pratikleri yeni bağlamlarda tanımlama, değiştirme gücü ve gündelik hayata temas eden dinamiği iç içe geçen bir görünüm sergilemektedir. Son yıllarda popüler kültür tarafından keşfedilmiş dini, mistik motifler, sadece kendisi olarak değil zamanın ruhuna uygun içeriklerle ve eğilimlerle dolaşıma girmekte, güncel bir bakışın, anlayışın yorumladığı yeni bir fenomen olarak durmaktadır (Aydemir, 2017, s. 156). Tüketim kültürünün muhtelif kanallarında karşımıza çıkan spiritüel-ezoterik anlam ve pratikler - örneğin yoga, meditasyon, Mistisizm, Sufizm - kitle iletişim araçları, kitap ve dergi sektörü, kişisel gelişim seminerleri ve eğitimleri, danışmanlık hizmetleri, turizm gibi tüketim kanallarında yerini almaktadır.

Geniş bir spekturumda seyreden spiritüel tüketim nesneleri her geçen gün artmaktadır. Sosyal medyada da spritüel pratiklere yönelik paylaşımlar gittikçe artan bir görünüm sergilemektedir. Örneğin özellikle Instagram’da yoga üzerine yapılan paylaşımlar genellikle orta sınıf, Batılı kadın imgeleriyle; görsel olarak bedensel "mükemmelliğe" yönelik çağrışımlar ile sürekli dolaşımdadır. Öte yandan spritüel anlamların çeşitli medya kanallarında inşa edilme ve söylemsel olarak kurulma biçimi, yüceltilmiş bir öznellik imgesi üzerine kurulabilmekte, bu anlamda narsisizm kültürünün değerler dizgesiyle benzeşen bir özellik de sergileyebilmektedir (Aydemir, 2018). Tüm bu örnekler tüketim kültürü ve kutsallık arasındaki ilişkiyi tartışmanın önemini vurgular niteliktedir.

Dinselliğin yeniden hâkimiyet kazanmasını postmodern iklimin bağlamına yerleştirebiliriz. "Mutlaklığın sorgulandığı bir evrede dinin ortaya koyduğu mutlak kutsallık kavrayışının geçersizleşmesi” her türden gerçeklik tasavvurunun ve büyük anlatıların yeniden inşasının mümkün göründüğü bir evrede kaçınılmazdır (Wenzel'den akt. Mirza, 2014, s. 51). Yekpare bir anlam dünyası yerine birbirinden farklı, çoğulcu ve eklektik yapısıyla karakterize olan Yeniçağ New Age düşüncesi, postmodern döneme özgü bir ideoloji olarak inancın bireyselleşmesinin radikal örneklerini ortaya koymaktadır (Paker, 2011, s. 70). Öncelikle bu eğilim dini ve din dışı öğeleri içine alarak eklektik bir yapı sergiler. Temel alanları şunlardır: Astroloji, rüya, simya, bitkisel tedavi, büyü, gizemcilik, alternatif tıp, Şamanizm, Hristiyan sembolizmi, Feng Shu, Taoizm, Zen budizmi, mistisizm, sufizm meditasyon, yoga vb. ( Brucéden akt. Köse, 2011, s. 134).

$\mathrm{Bu}$ mistik spiritüel akımlar ve maneviyat arayışları, modernleşme sürecinin derinleşmesi, kapitalizmin gaddarlaşması, rekabet, eşitsizlik ve yoksulluğun genişlemesi, rasyonalizasyon, dünyevileşme gibi makro süreçlerle; yabancılaşma, yalnızlaşma, anlam kaybı, güvensizlik, atomizasyon, bireyselleşme gibi mikro dinamiklerin iç içe geçtiği bir iklimin bağlamına yerleştirilebilir (Aydemir, 2017, s. 43). ${ }^{1}$ Söz maneviyat akımları inanç sistemlerini doktrinler üzerine değil tecrübe

1 C.Kozanoğlu New Age akımlarını pozitivist "ruh"un müdahale edemediği, tek tanrılı dinlerin ise bastıramadığı bir 
üzerine yapılandırmaktadır. Söylemlerinde determinizmden ziyade belirsizliği, teklik yerine çeşitliliği, sadeleştirme yerine farklılaştırmayı teklif etmekte (Possamai, 2002, s. 208) bu anlamda postmodern bir varoluş ortaya koyarak tüketim kültürünün postmodern karakterine uygun söylem ve pratikler de üretebilmektedirler.

Alternatif deneyimler, arayışlar öneren tüketim kültürü içerisinde spiritüel anlam ve pratikler de "özgün" ve "egzotik" çeşitlilik alanları, yaşam tarzı alanları olarak karşımıza çıkabilmektedir. Maneviyatın bireyselliğin dişa vurulduğu bir alana dönüştüğunü iddia edebileceğimiz bu süreç, postmodern tüketim kavramsallaştırmaları, bireyselleşme, ekonomik yapı, gündelik hayata dair fantezi ve arayışlar gibi dinamikler eşliğinde okunduğunda daha da anlaşılır hale gelmektedir. Bu çalışma, bu sürecin dinamiklerine ve güncel görünümlerine dair kavramsal bir tartışma yürütmeyi ve metateorik bir yöntem izlemeyi amaçlamaktadır. Çalışma, büyük oranda "olgunlaşmış ve zenginleşmiş tüketiciler” (Bauman ve Lyon, 2013, s. 125) için geçerli olacak söz konusu tartışmaları, tüketim ve kutsallık arasındaki ilişki dolayımıyla şu düzlemlerde ele almayı hedeflemektedir:

a) Bireyselliğin sergilendiği bir alan olarak kutsallık: Bireyin kendisini daha aşkın bir düzeyde gerçekleştirme imkânı sunması açısından ve doktriner olmaması açısından söz konusu manevi söylem ve pratikler postmodern bir tüketim kültürü içerisinde rahatllkla kendisine yer bulabilmekte, bireyin postmodern bir tüketim kültüründe bireysellik, farklılık ve yaşam tarzı inşa etmeye yönelik çabalarını kutsal bir hale ile kuşatılabilmektedir. Bu anlamda tüketim kültürü ve dinsel pratikler arasındaki ilişkiyi anlamak açısından, postmoderniteye özgü kategorilerle de bir dolayım kurmak gerekmektedir.

b) Spiritüel sembol ve anlamların kültürel tüketimi ve yeniden üretimi: Bu kavram, kutsalın bugünün arayış ve fantezilerine denk düşecek şekilde yeni bir bakış ve öznel yorum etrafında yorumlanması, inşa edilmesi dolayısıyla başka bir anlam ve bağlam içerisinde yeniden üretilmesine gönderme yapar. Ve bu süreç kutsal olanın kendi bağlamı, felsefesi ve tarihselliğinden koparılmasını da içermektedir.

manevi açlığa karşı bir arayış, merak olarak tanımlar. Söz konusu akımları tartışanların birleştikleri ortak nokta New Age hareketlerinin, Batılı toplumlar için hem bir dönemin ve kültürün hem de bir sektörün adı olduğudur (1997, s. 23-24). Kozanoğlu’nun aktardığına göre Batı’da Doğu öğretilerine, mistisizme merak modern öncesine kadar gitse de 1960'larda sonra bir akıma, toplumsal zemine dönüşmüştür. Casanova’nın "bireysel mistisizm ve spiritüel din" dediği bu akım, dinselliğin tipik modern - geç modern formlarının örnekleri olarak durmaktadır. Anlamı geçmişin bilgeliğinde arayan bu akımlar her geçen gün daha fazla insanı içine çekmektedir (1997, s. 31). Mirza’ya göre de mesele bu akımları oluşturan, öğelerin yeni ya da eski olmaları değildir, "mesele bu öğeleri yeniden yorumlayan, şekillendiren ve içeriklerini kazandıran zihnin yeniliğidir” (Başokçu’dan akt. Mirza, 2014, s. 15). Bir diğer yenilik ise Niedzviecki 'ye göre hem geleneğin konforuna yaslanmak hem de bu geleneği sınırlar koymayan bir şekilde yeniden yorumlamak şeklinde meydana gelmektedir. Niedzviecki’nin (2011) "hafif gelenek” olarak tanımladığı bu yapıda New age spiritüelliği, bireye kendisini yeniden inşa imkânı da sunmaktadır. Paradoksal bir şekilde hem geleneksel, yarı geleneksel bir yapıya ait olmak hem de o yapının kişinin "ben özelim" demeye devam edecek tarzda bireyselliğini yaşamasına ve keşfetmesine izin veren bir yapıdadır söz konusu alan (s. 82). Yenilik, modern anlayışın yaşamı dünyevi ve seküler olarak bölen kategorik bakışına bir cevap olarak da nitelendirilebilir. Mesele bir din ve inanç meselesi olmanın yanında moderniteye bir itirazı da barındırmaktadır içinde. Bu akımlar modern-postmodern bireyin "kendisine özgü” kişisel sorularına cevap verebilecek özelliklere, bireyin ruhsal deliklerini ne ile kapatacağına dair sonsuz söylem seçeneklerini de sahiptir. Böylece Yeni Dinsel Hareketler, her bireyin kendi ruhsal arayışını eklemleyebileceği bir yapı olarak cazibe odağına dönüşmektedir (Mirza, 2014, s. 15-18). 
c) Kutsal, spiritüel anlam, sembol ve pratiklerin meta-nesne olarak tüketim piyasasında yerini alış1.

Zygmunt Bauman (2013), postmodern versiyonuyla modernitenin, sürekli kendisini yeniden yaratma arayışı, spontanelik ve haz peşinde koşan özneler inşa ettiğini ifade eder (s. 10). Söz konusu moment, yeni duygular, hazlar ve deneyimler arayışındaki bireyin alışkanlıklarını da sabitlikten çok akışkanlık zemininde örgütleyen tüketim pratikleri üretir (Bauman, 2013, s. 25). Postmodern ya da geç modern dönemdeki ekonomik, toplumsal ve kültürel dinamikler dolayımıyla anlaşılabilecek bu süreçte, kendini geliştirme ve tasarlama ideali tüketim pratiklerinin merkezine taşınmaktadır. Postmodern - geç modern kültürde tüketim, kendini gerçekleştirme, yeniden kurgulama ve yaratma süreci olarak da deneyimlenmekte (Funk, 2013, s. 242-3) ve kimi bireyler için bu süreç maneviyat alanına taşınabilmektedir. Zira postmodern-geç modern uğrakta bireyselleşme dinamiklerinin iyice radikalleşmesi, benliğe, kişiselliğe odaklanmayı derinleştirdiği gibi bu süreç manevi olana teması da artırabilmektedir.

$\mathrm{Bu}$ çalışma açısından bunun önemi spiritüelliğin tüketim kültürü içerisindeki yerinin, benlik performansını arttırabilecek şekilde işlevselleşmiş olmasından gelmektedir. Zira "kişiselleşmenin, kendi olmanın ve kişiliği bulmuş olmanın" (Baudrillard, 2016, s. 102-103) olabildiğince yüceltildiği bir tüketim kültüründe spiritüel anlam ve içerikler bireysel bir mitoloji kurmanın, ayırt edici bir üslup ve tarz yaratmanın popüler ruhsal biçimleri haline gelebilmektedir. Bu anlamda bireyselliği yücelten bir tüketim kültüründe manevi pratik ve anlamlar da bu söylem ve eğilimleri tamamlayan, pekiştiren bir alan açmaktadır bireye. Kendini "mükemmel" hissetmenin, bedensel ve ruhsal bir "bilgeliğin" yol ve yöntemlerini sunan söz konusu pratikler hayat tarzı anlatısına spiritüel bir boyut katmakta, öte yandan metasal bir dolaşımla tüketim piyasalarında nesneleşebilmektedir.

\section{Toplumsal, Kültürel ve Sembolik Bir Süreç Olarak Tüketim ve Maddi Kültür Çalışmaları}

Sosyal bilimlerde kültürün maddi boyutuna her zaman ilgi gösterilse de geç modern toplumlardaki tüketim tartışmaları kültürel ve toplumsal bir bağlamı içerisine alacak şekilde genişlemektedir. Bu eğilim toplum teorisindeki "kültürel dönemeçle" de açıklık kazanmaktadır. Tüketim nesnelerinin "sosyal işaretler", "kimlik işaretleri”, "kültürel ve siyasal iktidarın taşıyıcısı" olarak kültürel ve toplumsal alanda iktidar ilişkileri kurma, toplumsal eşitsizliği yeniden üretme, anlam yaratma ve benlik, kimlik inşa etme gibi işlevlerini çeşitli kavramsallaştırmalarla ele alan çalışmalar, tüketim ve kültür arasındaki dolayımlı ilişkiyi çeşitli görünümleri ile sergilemektedir (Woodward, 2016, s. 1022).

Örneğin Mary Douglas ve Baron Isherwood (1999), Tüketimin Antropolojisi adlı çalışmalarında tüketim teorisinin aynı zamanda bir kültür teorisi ve gündelik yaşam teorisi de olmak zorunda olduğunu belirterek (s. 24) tüketimi salt fayda ve rasyonel tercih bağlamında ele alan iktisat teorilerini aşmaya çalışır. Malların pratik ve faydacı kullanımlarının dışında, iletişimsel işlevlerinin olduğunu söyleyen yazarlar (Douglas ve Isherwood, 1999, s. 75), aslında tüm maddi malların toplumsal ve kültürel anlamlar taşıdığını öte yandan toplumsal ilişkileri oluşturmada, kamusal 
anlamları yaratmada önemli işlevlere sahip olduğunu dile getirirler. Tüketim onlara göre bir anlam yaratma faaliyeti, toplumsal ve kültürel anlamların yaratıcı bir kanalı olarak görülebilir (Douglas ve Isherwood, 1999, s. 20). Ian Woodward'ın (2016) belirttiği gibi Douglas ve Isherwood, tüketimin "benlik, toplum ve kültürü oluşturmak için gerçek bir araç" haline geldiğini söyler. Tüketim benliği yapılandırmanın, sürdürmenin ve inşa etmenin aracıdır onlara göre (s. 137).

Daniel Miller de benzer bir anlayış ile tüketimin derinliksiz, anlamsız ya da dayatılan bir kültür olarak görülmesinden; baskıcı ve tahakküm aracı olarak ele alan kavramsallaştırmalar eşliğinde bir kenara atılmasından daha fazlasını hak ettiğini söyler. Tüketim indirgemeci yaklaşımlar etrafından anlaşılamayacak kadar dinamik ve karmaşık bir süreçtir. Buna göre tüketim yorumsamacı bir süreç olarak kişisel anlamların kurulduğu ve sürekli yeniden kurulduğu bir alandır. Miller, tüketimin baskılayıcı ve yabancılaştırıcı yanını merkeze alan mutlak "kötü" yönelimli kavramsallaştırmaları ya da özgürleştirici bir pratik olarak mutlak "iyi” olduğunu varsayan anlayışları aşmak ister. Böylece dikotomik karşıtlıklar üzerine kurulu anlayışlardan uzaklaşarak tüketimi hem maddi, pratik boyutuyla hem de anlam inşasına yaslanan kültürel boyutu ile kavramak gerekir (Woodward, 2016, s. 138-143).

Bu bağlamda hem kavramsal, soyut ve sembolik olanı içine alan tüketim, fiziki ve maddi olanı da kuşatmaktır. Başka bir ifade ile tüketim sürecini salt idealist, soyut, sembolik bir kategori olarak ele almak, kültürün maddi boyutunu gözden kaçırmak anlamına gelecek, tüketimin karmaşık doğasını ele almada yetersiz kalacaktır. Aynı şekilde tüketimi sadece üretim sürecinin bir uzantısı ya da nesne ile kurulan pragmatik bir ilişki bağlamında ele almak da tüketimin kavramsal, kültürel ve sembolik yanını göz ardı etmeye sebep olacaktır. Üstelik Woodward'ın da (2016) ifade ettiği gibi "maddi kültürün" - tüketimin hem fiziki hem de zihinsel, sembolik yanını kapsayan kültür maddi ve kavramsal boyutları arasındaki yapılan ayrım gündelik hayat pratikleri açısından yapay bir ayrımdır. Çünkü gündelik hayat içerisinde maddi kültür nesneleri, sembolik ve kavramsal anlamlar taşır ve sembolik ve fiziksel olanı birbirine bağlar (s. 23). Bu anlamda kültürel alan hem madde ve anlamın hem de özne ve nesnenin birbirinden kopuk olduğu değil, birbirini karşıllıklı olarak etkilediği, diyalektik ilişkiye girdiği bir alandır. Dolayısıyla tüketim kültürel, toplumsal ve ekonomik bir süreç olarak kavranmalı (Bocock, 1997, s.13), bu süreç özne ile de diyalektik bir şekilde dolayımlanmalıdır. Tüketim çalışmalarında "maddi kültür" yaklaşımı böyle kavrayışa yaslanır.

"Maddi kültür çalı̧maları" perspektifi, tüketimin salt materyalist, ekonomist indirgemeci kavrayışını aşma imkânı sunmakta, öte yandan tüketim sürecini anlam yaratma sürecinden tamamıyla kopuk bir "yanlış bilinç" meselesine ya da güdüp yönetici bir kültürün ideolojik tahakküm aracına indirgeyen anlayıştan da uzaklaşmaktadır. Dolayısıyla böyle bir kavrayış "maddi" olan ile "kültürel" olan arasındaki diyalektik ilişkiyi gözetmeyi mümkün kılar. Bu çalışma için "maddi kültür çalışmaları" yaklaşımının biçimlendirici bir etkisi vardır. Ancak bu çalışmada bir yandan tüketim ile toplumsal ve kültürel mekanizmalar arasındaki ilişkilere yoğunlaşılırken sürecin ekonomik sacayağını ihmal etmemeye de özen gösterilmektedir. Söz konusu kültürel üretimin ne tür bir ekonomik mekanizma yörüngesinde işlediğini anlamaya çalışmak, eleştirel bir kültürel yaklaşımı bütünsel bir kavrayışla zenginleştirmek açısından önemlidir. 


\section{Posmodern - Geç Modern Momentte Kimlik ve Bireysellik}

Modernite ve postmodernite ${ }^{2}$ arasındaki ilişkiyi her ne kadar kopuşlar çerçevesinde değil bir bütünsellik içerisinde değerlendirmek gerekse de yaşadığımız çağın “yeniliğini” karakterize eden bir takım kültürel, toplumsal ve ekonomik değişimler meydana gelir. "Yeni ve "eskinin” döngüsel ve akışkan bir şekilde birbirine dolayımlandığı bu momentte, "postmodern" olanı biçimlendiren yeni kimlik, anlam ve üslup biçimleri türer. Postmodern uğrak modernlikle kurduğu süreklilikve akışkanlık ilişkisine rağmen modern olanı da içeren ama ondan farklılaşan dönüşümlerle, bireysel kimlik ve benlikle de iç içe geçer. Zira kimlik zamanın ruhundan, sosyo-kültürel dinamiklerden ve toplumsal bağlamdan etkilenen bir nosyondur; her zamanın kendine özgü kimlik biçimleri, kimliğin kurulma dinamikleri ve bu kurulumun çeşitli alanları vardır. Bu bölümde geç modern ya da postmodern zamanlarda, bireysel kimliğin içinde oluştuğu yerleşik yapılardan etkilenerek dönüşümüne, bireyin "kendini gerçekleştirme" idealine ve bireysel kimliklerin kuruluşuna odaklanmaya çalışılacaktır.

Kimliğin modern ya da postmodern hali arasındaki süreklilik iddiası, Marshall Berman’ın (2006) modernlik deneyimine yönelik görüşleri etrafında açıklık kazanabilir. Modernlik deneyiminin kendisi bir belirsizlik, çelişki ve süreksizlik girdabıdır Berman’da (s. 27). Modernliğin 500 yılı aşkın tarihsel tecrübesinde birey modernite içerisinde değişen ve değiştiren bir güç olarak, modernleşme sürecinin hem nesnesi hem de öznesi olarak belirmektedir (Berman, 2006, s. 29). Modernlik tecrübesi, geleneksel kimlik ve rolleri alt üst etmektedir. Bu süreçte modern kimliğin kurulumu birey için çelişkili, kaotik ve sabit olmayan bir süreç olarak deneyimlenmektedir (Berman, 2006, s. 37-38). George Simmel de modernitenin bireye bilinçli bir ego anlayışı, yaratıcı bir tasarımcı rolü verdiğini öte yandan kişiliği de bir amaç haline getirdiğini ifade eder (Berman, 2006, s. 62). ${ }^{3}$

Ancak 20. yüzyılın sonunda modernliğin paradokslarının ve çelişkilerinin çoğaldığını inkâr etmek pek mümkün değildir. Bir taraftan maddi bolluk öte yandan artan bir yoksullaşma yaratan modernitenin çelişkileri artarak devam etmektedir (Hall, 1995, s. 114). Bu yüzden Anthony Giddens (2012) postmodern düşünürlerin iddia ettiği gibi moderniteden kopmuş bir döneme girilmediğini sadece modernliğin sonuçlarının radikalleştiği, evrenselleştiği ve derinleştiği bir "geç modern"

2 Modernite ya da postmodernite üzerine birikmiş devasa bir literatürü serimlemek bu çalışmanın sınırlarını aşmaktadır. Ancak günümüz posmodern ya da geç modern kültürünü anlamak ve bunun tüketimle olan bağını kurabilmek için, Jameson, Harvey ve Giddens'in görüşleri gelişkin ve bütünsel bir kavrayıș sunmaktadır. Zira üç düșünür de sürekli bir şeylerin bitip yenilerinin başladığı söylemi yerine, modern-postmodern arasındaki ilişkiye bütünsel bir şekilde yaklaşmanın önemini vurgular. Postmoderniteyi mutlak yeni bir toplumsal değişim olarak kavramaktansa kapitalist modernliğin içerisinde "ve onun kendi varlığında vücut bulan" bir değişim olarak (Best ve Kellner, 2016, s. 384-385) görmek açısından söz konusu düşünürlerin görüşlerine metnin çeşitli yerlerinde değinilecektir.

3 Elbette bu bireyselleșme sürecinin diyalektik ve çelişkili bir boyutu da vardır. Simmel'in belirttiği gibi modern kültürün başat özelliklerinden biri de "nesnel kültürün” "öznel kültür" üzerinde kurduğu baskıdır. Modern yaşamın kurumsal, teknolojik, ekonomik gelişmeleri bireysel hayatın çeşitli yönlerinde bir gerilemeye neden olur. Örneğin gelişmiş bir iş bölümü bireyi sınırlı bir alanda faaliyet göstermeye zorlar, tekdüze bir kalıba sokar. Bu yapı bireyselliği tehdit ettiği gibi bireyi bir totalite içerisinde eritme tehlikesini de içerisinde taşır. Modern örgütlenme bireyi araçsallaştıran, sistem içerisinde işlevselleştirip çeşitli konumlarda nicelleştiren bir özelliğe de sahiptir. Ancak birey bu gayri şahsiliği üreten örgütlenme karşısında kendi bireyselliğini ve kişiliğini koruma mücadelesi vermektedir. Bu boyutuyla "nesnel kültürün" "öznel kültürün" zayıflamasına neden olduğu için birey biricikliği vurgulama yönünde sürekli bir mücadele içerisindedir (2006, s. 100-101). Modernitenin bu çelişkileri ve diyalektiği Frankfurt Okulu düşünürleri tarafından da sorunsallaştırılır. Onlara göre modern kültürde "araçsal aklın" ve "kültür endüstrisinin" altında birey, özne olma bilincinden yoksun ve sahte bir bireysellik içerisinde yaşamaktadır (Adorno ve Horkheimer, 2014; Adorno, 2016). 
döneme doğru sürüklendiğimizi ileri sürer. Giddens çağdaş kültürde modernliğin ötesinde oluşan birtakım farklılıklar olduğunu kabul etmekle birlikte, modernitenin temel kategorilerinin örneğin kapitalist piyasa ekonomisi, endüstriyalizm ve ulus-devletin hala yerinde olduğunu söyler. Öte yandan postmoderniteye içkin olduğu iddia edilen belirsizlik, süreksizlik gibi dinamiklerin modernitenin nosyonlarından kaynaklandığı da ortadadır (s. 11).

Ancak Zygmunt Bauman’ın (2005) Bireyselleşmiş Toplum adlı çalışmasında belirttiği gibi bireyselleşme modern çağın erken zamanlarından farklı bir biçimde postmodern zamanlarda farklı anlam, biçim ve içerikler kazanır (s. 67). Fransız düşünür Lipovetsky ise benzer şekilde narsisizm kültürü ile de nitelendirilen geç modern ya da postmodern kültürde ikinci bir bireycilik devriminin meydana geldiğini söyler. Roller, normlar ve sınıfsal konumların merkezi olduğu bir dönemden bireyin tüketici olarak örgütlendiği, "makro" kimliklerden çok "mikro" kimliklerin önem kazandığ 1 bir değişim sürecidir bu. "Bu dünyada birey özerktir, potansiyelini arar, kimliğini inşa eder ve benliğin büyük serüvenine katılır." Bu süreçte özel faaliyet ve zevk alanları meydana gelmekte, yeni bireysel tüketim kanalları kurulurken zevkler de akışanlık kazanmaktadır (Lipovetsk'dan akt. Possamai, 2003, s. 210). Richard Sennet da (1996) narsisizm kültürünün kimlik ve kişilik arayışını merkezi bir mesele haline getirerek mahrem olanı yücelttiğini bu anlamda kamusal alanın aşınmasını pekiştirdiğini söyler (s. 405).

Cristopher Lasch (2006) Narsisizm Kültürü adlı kitabında ise sosyo-kültürel bir analiz yaparak modernite ve kapitalist ilişkilerin yarattığı değerler ekseninde yeni bir narsisizm kültürünün meydana geldiğini ve bu kültürün yeni bir kişilik yapısı ürettiğini iddia eder. Bu kişilik tipi, yaşamalarını herhangi bir yoldan iyileştirme umudu bulamayan, kişisel meşguliyetlerine gömülen ve ruhsal açıdan kendini geliştirme yolları arayan, kendini "Doğu’nun bilgeliğine kaptıran” özelliklere sahiptir (s. 23). Lasch' a göre hakim sosyo-kültürel paradigma, dünyayı değiştirme ya da daha iyi bir gelecek inşa etme gibi bir misyonu yerinden etmiştir. Birey artık tüm dikkatini kendi "kişisel icrası" üzerine yoğunlaştıracak, "kendi çöküşünün uzmanı olacak" ve "aşkın bir biçimde kendine yönelecektir" (Lasch, 2006, s. 25).

Belirsizliğin kendisi modern bir kategori olsa da postmodern uğrakta belirsizlik yaşamın temel bir işareti olarak okunabilir. Bauman’n (2013) ifade ettiği gibi postmodern moment modern yapıların görece sahip olduğu süreklilik ve sağlamlık duygusundan yoksundur ve bu durum bireysel kimliğin süreğenliği ve istikrarı açısından da bir parçalanma yaratmaktadır (s. 35-36). "Demir atacak istikrarlı bir zemin" bulamayan kimlik arayışları, "yüzergezer" bir benliğin kurulumuna sebep olmakta, çağdaş kültürde "çözülmemiş bir kimlik" sorunu da meydana gelmektedir (Bauman, 2013, s. 36 ve 42). Stuart Hall’a (1995) göre de "yeni zamanlarda" birey özne daha çok önem kazanmakta, "özne modelleri”ne yönelik kavrayışlar ve teoriler de değişmektedir. Postmodernizm ise "yeni zamanların" kültürel niteliğine gönderme yapan önemli bir işaret olarak karşımıza çıkmaktadır (s. 109-110).

Örneğin Fredric Jameson göre modern kimlikteki görece durağanlığın aksine postmodern uğrakta kimlik de bir dönüşüm geçirerek "çözüldü, parçalandı, bağlantısızlaştı ve modern benliğin ara sıra ulaşabileceği tözselliği ve tutarlılığı yitirdi." Böylece postmodern kimlik, daha çok boş zaman, tüketim ve imajlar aracilığıyla inşa edilen bir özelliği imlemeye başladı (akt. Kellner, 2004, s. 190-200). 
Bauman (2011b) modernlikten postmodernliğe geçişi teorileştirirken bu değişimin modernliğin "katılıklarından" postmodernliğin "sıvılaşmış" zamanına bir geçiş olduğunu iddia etmektedir. Merkezcil düşünce, üretim, sınıf gibi modern "katı" kategoriler, özellikle İkinci Dünya Savaşı’ndan sonra değişime uğrayarak erimeye başlamış; yerellik, bireysellik ve cemaat gibi kavramlar ön plana çıkmıştır (Bauman, 2011a, s. 53). Böylece "dünyanın yönetilme biçimiyle ilgili kaygının yerini, kendi kendini yönetme kaygısı” almaya başlamaktadır (s. 67).

"Postmodern insanın" karakter ve kişilik özelliklerini hem sosyolojik hem de psikanalitik açıdan ele alan Rainer Funk (2013) ise çağdaş kültürde kışkırtıcı bir "ben" vurgusunun git gide yaygınlaştığını ifade ederek özerk ve özgür olabilmenin hem bir ihtiyaç hem de keyif haline geldiğini söyler. Postmodern kimlik ona göre geleneksel düşünce ve ölçütlere göre çelişkili davranış özellikleri gösteriyor gibi gözükse de bireyin kendisi bunu bir çelişki olarak yaşamamaktadır. Bir tür "yamalı bohça kimliğe" sahip olan "postmodern insan", bir yandan "özgür ve spontane bir özerklik arzusu”na diğer yandan "ait olma ve bir ekiple birlikte olma arzusu"na da sahiptir (s. 11-12). "Saf bir kendini yaratma", "kronik bir kendini icat", "çok yüzlü benlik", "parçalanmış durum”, "yüzergezer kimlik yaşantısı" gibi kavramsallaştırmalar postmodern kimlik çözümlemelerine yönelik temalardır (FrankRieser'den akt, Funk, 2013, s. 63).

Anthony Giddens (2010) ise "geç modern", postmodern dönemde söz konusu benlik tipinin birey tarafından "refleksif (düşünümsel)" olarak tasarlandığını ileri sürer. Modernitenin geç modern koşullarında yoğunlaşan süreksizlikler ve riskler karşısında, bireyin tutarlı ve dengeli bir benlik oluşturması git gide önem kazanmakta; "ne yapmalı" ve "nasıl biri olmalı" sorusu geç modern zamanlarda merkezi bir soru haline gelmektedir (s. 53 ve 98). Öte yandan geç modern koşullarda bireyler sadece belirli bir yaşam tarzını sürdürmek zorunda değil aynı zamanda bir yaşam tarzı inşa etmek zorunda da kalırlar. Giddens’a göre (2010) hayat tarzı bireysel kimlik inşasına maddi bir biçim kazandırmakta, bir kimlik anlatısı kurmanın ve bireysellik inşasının özüyle bağlantılı hale gelmektedir (s. 110-111). Elbette bu süreç ekonomik bir arka planı da içine almakta, artan bir bireysel kültürün ardındaki piyasanın taleplerini, istikrarsızlı̆ını ve esnekliğini de yansıtmaktadır (Giddens, 2010, s. 37-40). Bu anlamda kimliğin tutarlı ve sabit bir anlatı üzerine inşa edilememesi yeni ekonomik düzen açısından da bir "rasyonalite" taşımaktadır. Dolayısıyla geç modern ya da postmodern toplumlarda "sermaye olarak kimliğin" (Woodward, 2016, s. 188) ortaya çlkma süreci, postmodern kimlik, dışavurumcu tüketim tarzları ve ekonomik dinamikler arasındaki ilişkiler bağlamında da anlaşılmalıdır.

Richard Sennett (2002) kimlik ve ekonomik sistem arasındaki dolayımı Karakter Aşınması: Yeni Kapitalizmde İşin Kişilik Üzerine Etkileri adlı çalı̧̧masında bir baba oğul hikâyesi üzerinden çözümler. Ona göre yeni kapitalizm kültüründe, esnek üretim modeli birey üzerinde yeni bir karakter aşınmasına yol açar. Bu yeni çalışma düzeni ve etiğinde üretim sisteminin, iş zamanı ve mekânının esnekleşmesi aynı zamanda iktidarın da esnekleşmesine, merkezsizleşmesine yol açar. "Uzun vade yok" sloganıyla işleyen yeni kapitalist düzen bir yandan yoğun bir belirsizlik, güvencesizlik ve istikrarsızlık üretirken geçici yüzeysel ilişkiler ve benlikler de oluşturmaktadır (s. 11). Zira esneklik koşulları bireyden her ortama uyum sağlamasını talep etmekte; akışkan, her zaman değiştirilebilir olma özelliği ile "insanın karakterini süre giden bir anlatıya dönüştürmesini" engellemektedir 
(Sennett, 2002, s. 30). Böylece Yeni Kapitalizm Kültürü’nde (Sennett, 2015) birey için idealleştirilmiş bir benlik imgesi ortaya çıkmaktadır: "Kısa vadeye yönelmiş, potansiyel yeteneğe odaklanmış, geçmiş deneyimleri terk etmeye razı olan" (Sennett, 2015, s. 12) sürekli yeni beceriler öğrenen ve bunları sürekli güncellemek zorunda olan bir benlik imgesidir bu (Sennett, 2015, s. 38).

John Urry Örgütlü Kapitalizmin Sonu (1995) başlıklı çalışmasında politika, kültür ve toplumsal yaşamın artık toplumsal sınıflara göre örgütlenmediğini söyler. Küreselleşme, üretim sistemindeki dönüşüm, sermaye ve emek arasındaki ilişkilerin değişen niteliğii, sermayenin uluslararalılaşması gibi süreçler sadece kapitalist üretim sürecini değiştirmekle kalmamakta, kimlik ve bireysellik meselesi ile de dolayımlanmaktadır. Kapitalist sistemdeki dönüşüm, bireyselliği ve kişisel kimliği ortaya koymanın önemini git gide arttırmakta, öte yandan toplumsal kimliğin kolektif, sınıfsal yanını törpüleyip kimliğin öznel yanını yüceltmektedir. Kolektif bir yapılanmanın parçası olmak, toplumsal bir takım ideallerin peşinden koşmak yerine, radikal bir bireycilik kültürü içerisinde ideal olan yaşamı bir proje haline dönüştürmek, bireyselliğin stratejik ve performatif kurulumuna odaklanmaktır. Geç modern koşullarda "kendini gerçekleştirme" ve bireysellik tasarımı piyasanın kriterleri çerçevesinde kurulacak metalaşmış bir kimlik inşasını da beraberinde getirebilir Giddens’a göre (2010, s. 248). Andrew Wernick (1996) de erken kapitalizmin "mülkiyetçi birey"inin, geç kapitalizmde yerini "promosyoncu birey" tipine bıraktığını söyler. Sadece metaları sahiplenmekle yetinmeyen, aynı zamanda kendini de bir meta olarak kuran ve sunan yeni bir "birey" tipidir bu (s. 291).

Bu bireycilik, tüketim piyasası tarafından hem beslenen hem de yeniden üretilen bir karaktere sahiptir. Geç modern koşullarda tüketim, yaşamın yabancılaştırıcı yanlarına yönelerek onları sağaltacağını iddia eder (Giddens, 2010, s. 218). Bu anlamda spiritüel anlam ve pratiklerin de tüketim kültürü içerisinde sağaltıcı "işlevi” vardır, bu yüzden her geçen gün yaygınlık kazanmakta ve kendisine özgü spiritüel bir piyasa da yaratmaktadır. Başka bir ifade ile yarattığı krizi ve tahribatı fırsata çevirebilen bir sistem açısından her türden sembol, imge, anlam ve ritüel tüketim kanallarında yerini alabilir, bireylerin farklılık ve kendilik arayışlarına bir çare olarak sunulabilir ve bu kanallarda metalaşabilir nitelik sergilemektedir.

Bauman’nn da (2003) ifade ettiği gibi “pazar, ürettiği mutsuzlukla beslenmekte", yarattığı kişisel yetersizlik korkuları ile hem tüketimi meydana getirmekte hem de kendi meşruiyetini yeniden üretmektedir (s. 225-226). Mutsuzluklardan ve anlam arayışından beslenen danışmanlık ve terapi sistemleri de geç modern koşullarda böyle bir narsistik kültürel bağlamdan türer. Lascha göre kişisel gelişim endüstrisi ve uzmanlık sistemleri paternalist bir nitelik sergiler ve bebeksi bir kendine yetersizliği de pekiştirir (akt. Giddens, 2010, s. 219). Benzer şekilde Funk da (2013) sürecin otoriteye duyulan inançla ilişkili olduğunu ve kendilerini bilge bir otorite olarak kuran danışmanlık ve uzmanlık sistemlerinin kendilerine yönelik bir bağımlılık ilişkisi de meydana getirdiğini ifade eder (s. 218). Tüm bu değerlendirmeler ş̧ı̆̆ında söz konusu momentte benlik ve bireysel kimliğin dinamikleri, geçirdiği dönüşümler, öznelerin tüketim kültüründe var olma deneyimlerini, tüketimle kurdukları ilişkiyi şekillendiren önemli kurucu süreçler olarak karşımıza çıkmaktadır. 


\section{Postmodernite, Tüketim Kültürü ve Bireysellik}

Tüketime yönelik postmodern kavramsallaştırmalar, "bireysellik", "farklılaşma ihtiyacı", “özgünlük”, “yaşam tarzı”, "dışavurumculuk” gibi temalar etrafında kurulmasına rağmen tüketimin söz konusu kavramsallaştırmaları sadece postmodern ya da geç modern zamanlarlara özgü değildir. Bireyin tüketim üzerinden bireyselliğini sergileme, kurgulama ihtiyacı da sadece postmodern zamanlarda ortaya çıkmış bir mefhum değildir. Örneğin Don Slater Consumer Culture and Modernity (1997) adlı çalışmasında bireysellik, kişisel orijinallik, yaratıcılık, kimlik arayışı gibi temaların sadece postmodern döneme özgü olmadığını, köklerinin Aydınlanma’ya, Romantik döneme kadar götürülebileceğini tarihsel bir analiz sunarak iddia etmektedir. Aynı kimliğin postmodern hallerinde olduğu gibi bu temalar da içerisinde modern olanı barındırmakta, bir sürekliliği temsil etmektedir (1997). Dolayısıyla tüketim kültürü modern bir kategori olsa da postmodern eğilimler sergileyerek yeni biçim ve içeriklere kavuşabilmektedir (Featherstone, 2013).

Örneğin 20. Yüzyılın Berlin'inde George Simmel (2006), metropol hayatı, moda ve bireysellik meselelerine ilişkin bir analiz yaparak bireyin kimliğini, kişiselliğini ve otonomluğunu kurmaya yönelik isteğini modern kültürün çatışmalı ve çelişkili görünümleri üzerinden analiz eder. Simmel’e göre (2006) kentler gelişmiş iş bölümü mekânları olarak uzmanlaşma sistemleri yaratmakta bu süreç bireyler arası ilişkileri de ekonomik bir ilişkiye, bir kazanç ve rekabet ilişkisine benzetmektedir. Uzmanlaşma süreci kamusal beğeni ve ihtiyaçlarda bir inceliğe ve farklılaşma eğilimine neden olur. Modern kültürde kişiselliği, bireysel farklılığı vurgulamanın bu kadar önemli olmasının temelindeki önemli dinamiklerden biri bu ekonomik süreçtir. Ekonomik yapı, bireyden diğerlerinden farkını belli edecek bir özgünlük beklemekte, sivrilen, parlayan, göze çarpan özelliklerle donanmasını istemektedir. Öte yandan metropoldeki ilişkilerin, seyrekliği, kısalığı ve sabit olmayışı, bireyi dikkat çekici olmaya, kendini hakiki bir şekilde sunmaya, ifade etmeye de yöneltmektedir. Böylece kişi öz imgesini başkalarının bakışında çarpıcı ve kolay unutulamaz kılmak istemektedir (s. 97-100).

Simmel için modernlik analizinde mekân çok önemli bir çıkıs noktasıdır çünkü tüketim ve modaya yönelik düşüncelerini şehir yaşantısı üzerinden geliştirir (Frisby, 2012, s. 97). Simmel (2006) için moda bireyin hem bir bütünün içinde erime, uyumlanma ihtiyacını hem de ayırt edici olma, farklı olma, aykırı olma ihtiyacını karşılamakta (s. 106-7) toplumsal bir dolayımla kişinin bireyselleşme ihtiyacını gidermekte (Simmel, 2006, s. 121) ve Modern Kültürdeki Çatışmảnın (2006) fragmanlaşmış görünümlerini sunmaktadır. Bu anlamda Simmel tüketimin geç modern, postmodern dünyada aldığı yeni görünüm ve biçimlerin sürekliliğini vurgulamak açısından önemli bir noktada durmaktadır.

Tüketimin modern ve postmodern görünümleri arasındaki ilişki kopuşlarla değil sürekliliklerle ilerleyen bir ilişki olsa da kapitalist üretim mantığındaki yeni ilkeler, tüketimin doğasını, niteliğini ve görünümlerini değiştirmektedir. Geç modern ya da postmodern momentte özneler, modern dönemden farklı olarak üretici rolleri ile değil tüketici rolleri ile değer kazanmaya başlamış; kültür, bireyleri bu tüketici rolünü oynama ve benimseme yönünde gönüllü hale getirerek hegemonik bir sürece de sokmuştur (Bauman, 2012, s. 84). Ancak Robert Bocock’un (1997) belirttiği gibi 20. yüzyılın sonlarından itibaren kültürel ve toplumsal alanda bir dizi değişiklik meydana gelse de modern ve postmodern kültür ve topluma dair çözümlemelerin ardında, kapitalizm hala temel 
kuramsal kavram olma niteliğini sürdürmektedir. Çünkü söz konusu değişim ve dönüşüm süreci kapitalist üretim sistemi içerisinde meydana gelmiştir (s. 40). Bu anlamda kapitalizmin geçirdiği dönüşüm postmodernite ve tüketim arasındaki ilişkiyi anlamak açısından oldukça önemlidir.

Fordizmden postfordizme geçiş süreci fordizmin kitlesel tüketimi varsayan eğilimini değiştirmiş, postfordist üretim mantığı da tüketimi kitlesel olandan bireysel olana, rasyonel, faydacı ve ihtiyaç temelli olandan daha duygusal, sembolik ve dışavurumcu olana kaydırma da önemli bir yapılandırıcı süreç olarak belirmiştir (Murray, 1995, s. 48-53). "Çalışma etiğinden” "tüketim estetiğgine" geçiş olarak da adlandırılabilecek bu süreçte (Bauman, 1999, s. 39-52) tüketici gruplar fordist dönemden farklı olarak demografik özellikleri üzerinden değil yaşam tarzları üzerinden değerlendirilmektedir (Slater, 1997, s. 185). Bu süreçte moda ve tüketimde bireysel olana dönüş meydana gelmekte, kapitalist mantık "kişiselleştirilmiş" mallar bolluğu, bireyselliğini yansitacak sembol ve ürünler üretmektedir (Niedzviecki, 2011, s. 41-43). ${ }^{4}$

Ancak Stuart Hall'un da (1995) belirttiği gibi postfordizmin önemi sadece ekonomik bir dönüşümü değil kültürel ve toplumsal bir dönüşümü de işaret etmesinden gelmektedir. Postfordizm tüketimin bireyselleşmesi kadar, eski kolektif kimliklerin zayıflamasına, toplumsal parçalanmanın artmasına ve yeni kimliklerin ortaya çıkmasına etki eden, bu anlamda kültürel ve toplumsal sayacakları da olan geniş bir fenomendir (s. 107-109). Postfordizm estetik tasarım, stil, teknoloji ve ürün farklılaştırılması gibi üretim dinamiklerini çoğaltarak kişisel imgeler üretmeye dayalı bir tüketim kültürünü de genişletmektedir (Hall, 1995, s. 118). Bu süreçte tüketim kültürünün "yeni kahramanları" açısından hem tüketim pratikleri hem de yeni tecrübe ve deneyimler bir yaşam tarzı inşa etme yolunda git gide önemli hale gelmektedir (Featherstone, 2013, s. 154-155).

Tüketimdeki bu yeni bireyselleşme süreci, aile, sınıfsal konum ya da kolektif grupların tüketim kararlarını belirleme gücünden yoksun oluşuna da gönderme yapmaktadır. Benliğin inşasında özgür ve özerk olan birey, aktif bir karaktere bürünmekte, sorumluluk ve risk alarak "müteşebbis tüketimciler" olarak kimliğini adeta bir proje olarak yaratmaktadır (Lash ve Urry'den akt. Woodword, 2016, s. 38). Bauman’n (2003) ifade ettiği gibi “yaşam tasarısı”nı bir gereksinim haline getiren bu süreç; deneyim, keşif, cesaret ve risk gibi nosyonları tüketimin merkezine doğru bir seyirle taşımaktadır. Böylece tüketim piyasası bireyin beceri ve özgüvenini hem besleyebileceği hem de sergileyebileceği bir alan da açmaktadır (s. 197-8).

Fredic Jameson da (2005) postmoderniteyi toplumsal ve ekonomik yaşamda ve kapitalizmin kendi yapısal dinamiklerindeki değişim süreciyle birlikte değerlendirir. ${ }^{5}$ Ona göre postmodernite

4 Postmodernizm ve kapitalizm arasındaki ilişkiyi kavramsallaştırması açısından D. Harvey’in düşüncelerine değinmek bu noktada yararlı olacaktır. Harvey Postmodernliğin Durumu (1997) adlı çalışmasında, postmoderniteyi modernitenin uzantısı olan özgül bir durum ve ekonomik sömürünün kemikleştiği yeni bir paradigma olarak betimlemektedir. Ona göre postmodernite imajlar, pazarlanabilir estetik, kültürel metalaşma, neoliberal ekonomik düzenin kurulduğu bir momente işaret eder. Ona göre modernlik ve postmodernlik arasındaki ilişkiyi Fordist Modernlik ve Esnek Postmodernlik şeklinde bir şemayla da kavramsallaştırabilir. Böylece postmodernite postfordist bir üretim sistemi ve kültürüne dayalı toplumla özdeş değilse bile epey uyumlu bir tablo çizmektedir.

5 Jameson'da, postmodernite "kültürde yeni biçimsel özelliklerin doğuşunu, çoğu zaman örtmeceli biçimde moderleşme, sanayi sonrası ya da tüketim toplumu, medya ya da gösteri toplumu veya çok uluslu kapitalizm denilen yeni bir toplumsal yaşamla ve yeni bir ekonomik düzenle ilişkilendirmek olan dönemleştirici bir kavramdır” (2005, s. 15). 
açısından kültürün önemli göstergelerinden biri, metalaşma süreçlerinin tüm toplumsal ve kültürel alanlara yayılmasıdır. Bu metalaşma süreci postmodernizmin temel özelliklerinden olan parodi, pastij, taklit, "öteki biçemlerin aşırı kullanımları (aşırma, mannerisms)" ve "biçemsel seğirme (twitches)" gibi nosyonları kapsamakta, kültürün toptan metalaşmasına gönderme yapmaktadır (s. 15-16). Jameson’un, kültürel alanda meydana geldiğini düşündüğü diğer değişimler ise; yüksek kültür ile aşağı kültür arasındaki ayrımın çökmesi, modernist eserlerin eleştirel yönlerini yitirmesi, kapitalizme meydan okurken başvurulabilecek eleştirel mesafenin muğlâklaşması, farklı bir gelecek tahayyülüne olan inancın yitirilmesi ve yön kaybına neden olan hiper-uzamın ortaya çıkması şeklinde, özetle bir imaj, simülark, şifozreni evreni şeklinde özetlenebilir (akt. Best ve Kellner, 2016, s. 258-262).

Tüketimi postmodernite çerçevesinde kavramsallaştıran açıklamalar, tüketimi çağdaş kültür ve toplumun başat bir dolayım alanı olarak ele alır ve onu toplumsal, kültürel değişim süreçlerinin merkezine yerleştirir. Temel savları, aşırı metalaşma süreçlerinin tüketimi göstergebilimsel ve estetik bir temele oturttuğu yönündedir. Bugün tüketimin pragmatik boyutunun yanında dışavurumcu, kimlik inşa edici, düşünsel ve oyuncul boyutlarının da olduğu göz önünde bulundurulduğunda bu görüşe katılmamak mümkün değildir. Ancak "postmodern bir kutsama" etrafında tüketimi salt özgürlük, kimlik oluşturucu bir güç ya da estetik bir fenomen olarak ele almak, kültürün maddi boyutunu göz ardı etmek anlamına gelebileceği gibi, kültürel alandaki iktidar ve güç ilişkilerini de ekonomik, toplumsal, kültürel - önemsememekle sonuçlanabilir (Woodward, 2016, s. 35-36).

Featherstone'un çağdaş tüketim kültürünü postmodernite bağlamında çözümleyişi böyle bir kutsayıcı anlayıştan uzaktır. O tarihsel süreçte ve kapitalist üretim ilişkilerindeki dönüşümle birlikte modern-postmodern arasındaki sürekliliği vurgular ve tüketim kültürünün güncel niteliğini gelişkin bir düzeyde kavramsallaştırır (Featherstone, 2013). Ona göre postmodern tüketim kültüründe yaşam tarzları, bireysellik merkezi bir mesele haline gelir, tüketimde haz ve arzunun rolü kurucu bir niteliğe kavuşur, tüketim sadece pragmatik bir zemine değil iletişimsel bir zemine oturur, gündelik hayat içerisinde yaşamı estetize edici bir güce kavuşur ve kimlik ve benlik ile dolayımlanır (Woodward, 2016, s. 36).

Yavuz Odabaşı̀na göre (2004) "postmodern benlik, tüketim ve deneyimle belirlenen bir olgu olarak tanımlanabilmektedir” (s. 119). Modern ve postmodern tüketici arasında daha kategorik bir ayrım yapan A. Fuat Firat ve Clifford J. Schultz (2001) ise modern özneden farklı olarak postmodern tüketicinin farklı kimlikler ve değerler benimseme konusunda daha rahat, esnek ve "merkezsiz" olduğunu, maddi zenginlik kadar deneyim ve tecrübe arayışında da güçlü bir motivasyonunun olduğunu ifade eder (2001, s. 201).

Rainer Funk (2013) da benzer bir şekilde "postmodern ben odaklı" karakter için yaşantı alanları estetize etmenin ve yaşam tarzı kurmanın çok önemli olduğunu söylemektedir. Bu eğilim kendini gösteriye dönüştürmekten alınan bir keyif alanı da yaratmakta, bu süreçte her şey bir benlik performansı için araç haline gelebilmektedir. Funk, söz konusu birey için tutarlı bir üslup takıntısının olmadığını, farklı üslupları yan yana bünyesinde taşıyabileceğini söyler. Değerlerini ben odaklı bir biçimde belirleyerek kendisini dışsal bir belirleyiciden azade kılan "postmodern karakter" 
için en önemli değer kendini ifade etmek, kendi olmaktır (s. 70-73). Kendi ben’ini üretmeye olanak tanıyan tüketim ve boş zaman pratikleri kimileri için dinsel alana da taşınmaktadır. Postmodern tüketim kültürü içerisinde egzotik ve yadırgatıcı olana karşı kültürel açılılk (Funk, 2013, s. 68-70) kendilik inşası ve bireyselliği sergileme eğilimlerini dinsel - yarı dinsel anlam ve pratikler alanına da taşımakta, tüketim kültürü içerisinde var olma biçimi, spiritüel anlam ve pratiklerle kurulan ilişki biçimini de değiştirmektedir. Süreç söz konusu kutsal biçimlerin tüketim kanallarında metalaşmasını da kapsamaktadır.

\section{Postmodern Spiritüellikler, Tüketim ve Bireysellik: Nesne-Meta Olarak Kutsal, Kutsal Olanın Kültürel Tüketimi ve Yeniden Üretimi}

Geç modern ya da postmodern kültürde hayat tarzı "bireyselliği, kendini ifade etmeyi ve üslupçu bir özbilinci” imler (Featherstone, 2013, s. 149). Söz konusu dönemde yaşam tarzlarını, bireyselliklerini beslemek isteyenler için dinsel-manevi alan da diğer hayat tarzları gibi seçilebilen bir alandır (Giddens, 2010, s. 184). Popüler spiritüel anlam ve pratikler geç modern koşulların çelişkileri, ikilemleri ve birey üzerindeki tahribatı üzerinden de türemekte, farklı pratik ve felsefeler ile kültürel alanda yerini almaktadır. Para ve zaman gerektirdiği için elbette sınıfsal bir ayrıcalık da barındırmaktadır içerisinde (Giddens, 2010, s. 227). ${ }^{6}$

Tüketim baskıcı bir süreç olarak değil, "cezbetme ve ayartma üzerine kurulu” (Bauman, 2012, s. 83) ve baştan çıkarılmaya gönüllü özneler inşa ederek ilerleyen bir süreç (Bauman, 2012, s. 87) olarak düşünüldüğünde tüketim kültürü içerisindeki söz konusu tinsellikler sadece piyasanın dönemsel arayışları bağlamında değerlendirilmemeli, bireyin eğilim ve ihtiyaçlarını kuşatan bu anlamda gündelik hayatı ve kültürü de içerisine alan bir alan olarak kavranmalıdır.

Geç modern-postmodern süreçlerde bireyin dinselliğini tecrübe etme biçimi genel ekonomik ve toplumsal süreçlerden bağımsız gerçekleşmemekte, kişi dış dünya ile ilişkisini tüketim kanalı üzerinden kurdukça, dinle olan ilişkisi de bu iklimden etkilenmektedir (Mirza, 2014, s. 55). Böylece kutsal olan söz konusu süreçlerde kendi pazarını yaratmakta hem de bireyselliği süsleyen, yaşam tarzı kuran sembolik anlamlar kazanmaktadır. Bireyin kutsal olana yönelik arayışları üzerinden kendi meşruiyetini sağlayan spiritüel tüketim alanı, bir yandan meta ve nesne olarak kutsalın çeşitli görünümlerini içermekte öte yandan kutsal anlam ve felsefelerin bugünün eğilim ve ihtiyaçlarına denk düşecek şekilde yeniden yorumlanmasını da sağlamaktadır. Tüketim kültürü içerisinde kutsal ve seküler arasındaki uzlaşılar ve eklemlenmeler, kutsal olanı ekonomik "rasyonellik" taşıyan bir kaynağa, "dünyeviliğin" lehine işleyen bir sermayeye dönüştürebilmenin yanında (Taburoğlu, 2008, s. 202), yaşam tarzlarını süsleyecek anlamların sembolik ve kültürel tüketimini ve yeniden üretilişini de kapsayabilmektedir.

6 Kendini gerçekleştirmeyi, kişisel dönüşümü, tatmin edici bir kimlik ve bireysellik inşa etmeyi salık veren popüler kültür ürünleri, en çok “yeni orta sınıf, yeni işçi sınıfı ve yeni zengin ya da üst sınıflar” açısından anlamlıdır (Featherstone, 2013, s. 48). D. Swartz da Bourdieu üzerinden yola çıkarak postmodern bir tüketim kültürünün stili çok önemseyen orta sınıf içerisindeki yeni küçük burjuvaziyi bu kültürün taşıyıcısı olarak kurduğunu söyler. Deneyim, yenilik ve en moda mallar peşinde koşma, bunlara sahip olma üzerinden kendisine bir yaşam tarzı ve bireysellik inşa etme, bunu süreğen bir proje haline getirme uğraşısı kendisini en çok bu sınıf içerisinde göstermektedir (Swartz, 2015, s. 250). 
Featherstone postmodern tüketim kültüründe ortaya çıan yarı-dinsel, dinsel anlam paternlerini, Max Weber’in "dinin manastırın kapısını çarpıp çıktıktan sonra dünyevi olayların piyasasına doğru geniş adımlarla yürümeye başladığı” yönündeki metaforuyla bağlantılı bir düzlemde tartışır. Çağdaş kültürde din tüketim kültürü içerisinde öbür anlam sistemleriyle yan yana durmakta, hayat tarzı pazarlayan piyasa anlayışında "paketlenmiş bilgi öbekleri" olarak boy göstermektedir. Ayrıca "anın peşinden koymayı", "hedonizmi”, "hayatın üsluplaştırılmasını" ve "estetikleştirmesini” yücelten bir tüketim kültüründe, kutsal anlam ve pratikler de tüketim kültürünün söz konusu temalarıyla uyumlu hale gelmekte öte yandan tüketimci bir ethos çevresinde yeniden yorumlamalara maruz kalmaktadır (Featherstone, 2013, s. 196-197). Yeniden yorumlamalar, eklemlenmeler, uzlaşılar ve çelişkiler şeklinde cereyan eden bu süreç, tüketim kültüründe var olma deneyimlerini maneviyat alanına da taşımakta, tüketim kültürünü kutsal anlam ve biçimlerle donatmaktadır.

Jeremy Carrette ve Richard King (2005) Selling Spirituality başlıklı çalışmalarında, ekonomi politik bir bakışla kapitalist mantıkla sarmaş dolaş olmuş "maneviyat" pazarının yaygınlık nedenlerini sorgular. Onlara göre ilk olarak Aydınlanma süreciyle gelmiş olan alternatif dini alanlar keşfetme özgürlüğü önemli bir biçimlendirici süreç olarak değerlendirilebilir. Buna göre bu seçim özgürlüğü pazar için de bir özgürlük ve yayılım alanı açmaktadır (s. 13-14). Geç modern toplumlara sızan spiritüel akımlar bir yandan neoliberal ideolojiler tarafından paketlenmekte öte yandan hem bireysel hem de kurumsal amaçlar uğruna araçsallaşabilmektedir. Kutsalın "kültürel sermaye" olarak sunumu, (bedensel ve ruhsal tedavi yöntemleri, sosyalleşme, vb. içeriklerle müşteriye pazarlanması) çağın tüketimci ethosu ile uyumlu bir tablo çizmektedir. Spiritüel pazarda Antik Asya dinlerine, Doğu bilgeliğine ait anlam ve içerikler; spiritüel vücut spreylerinden, Zen deodorantlarına, otantik ve mistik temalı giysilerden, manevi teknikler ile bireysel verimliğini arttırmaya yönelik pratiklere kadar geniş bir spektrumda dönüşüme uğramakta, metalaşmaktadır (Carrette ve King, 2005, s. 15-16).

Carrette ve King 'in (2005) "kapitalist ruhsallıklar" adını verdikleri bu araçsal maneviyat biçim ve içerikleri, aynı zamanda şirket amaçlarını teşvik eden bir ruhsallık alanı da inşa edebilmektedir. Başka bir ifade ile bireyin spiritüel açıdan kendini gerçekleştirme amacı ve endişesi de ekonomik düzenin daha verimli çalışabilmesi açısından araçsallaştırabilmektedir (2005, s. 20). Böylece maneviyat dili var olan ekonomik sistemi besleyen bir kaynağa dönüşmekte, Eric Fromm’un ifadesiyle "Tanrı iş ortağı olmaktadır" (akt. Carrette ve King, 2005, s. 24).

Mara Einstein (2008) da Amerika'da son yirmi yll içerisinde adeta bir "spiritüel market" meydana geldiğini ifade eder. Ruhsal eğilimlerin ve kapitalist piyasa ekonomisinin iç içe geçtiği bu tabloda birçok spiritüel anlam ve semboller hem kitle iletişim araçlarında hem de tüketim kanallarında bir dizi eklemlenmeler meydana getirmektedir. Maneviyat içerikli kitap sektöründen, spiritüellikle donanmış film, dizi ve tiyatro endüstrisine, spiritüel macera vaat eden turizm sektöründen dini konferanslar ve seminerlere kadar her yer kutsallıklarla donanmakta; popüler kültür içerisinde paketlenebilmektedir (s. 1-7). Tayfun Atay’a (2004) göre böyle bir süreç dinin postmodern döneme bir "kültürel sermaye" ve tüketim değeri olarak geri dönüşünü de simgelemektedir (s. 99).

Ulusal kültürde de İslami bir kimliğin uzantısı olarak görülebilecek dini pazarın yanında İslam’nn mistik felsefelerinin de kendilerine özgü spiritüel bir pazar yarattığına şahit olunmaktadır. Örneğin 
son yıllarda tasavvuf felsefesine ait anlam ve semboller hem popüler kültürü hem de tüketim kanallarını besleyen ve o kanallarda türlü biçimlere dönüşen bir kaynağa dönüşmektedir. Mevlana ve Mevlevilik kültürüne ait biçim ve içerikler bir yandan imgesel, ikonik, metasal bir dolaşımla popüler kültüre eklemlenmekte, öte yandan liberal-neoliberal, muhafazakâr-dini ve postmodern görüşlerin uzlaşı alanı olarak iş görmektedir (Aydemir, 2017).

Kültürel alanda kutsal ve seküler olan arasındaki bu ilişki biçimleri, tüketim kültürünün postmodern karakteri bağlamında değerlendirebilecek bir özellik de barındırmaktadır. "Yüksek" kültür ile "ticari” kültür arasında birleşme, ticari kültürün her yana sızışı, farklı biçimleri bir araya getirme yöntemi olarak pastij, özgün olanı parodileştirme, biçimsel yeniliğin zor olduğu bir kültürde geçmişe öykünme, taklit ve aşırma gibi özellikler (Jameson, 2005, s. 15-18 ve 30-31) postmodern bir momentte kutsallığın aldığı görünümleri de imler niteliktedir. Zira Jean Baudrillard’nn ifade ettiği gibi postmodern kültür, geçmişe ait kültürlerin, geri getirilmeye çalışıldığı, "geçmiş bir kültürün restorasyonuna" yönelik eğilimlerin yaygınlaştı̆̆ bir ortama da işaret etmektedir (akt. Kellner, 2000, s. 377). Dolayısıyla popüler kültürün postmodern karakteri yaygınlaştıkça geçmişin birçok biçimine yönelik yerinden edici müdahale tavrının da yaygınlaşması söz konusudur denilebilir.

Hal Niedzviecki'ye göre (2011) Batı toplumlarında 1980’lerden sonra yaygınlaşan New Age spiritüelliği, geleneksel dinin talep ettiği teslimiyet, sorumluluk ya da fedakarlık yerine, bireyselliğin sürdürülmesine olanak tanıyan bir ethos inşa etmekte bu anlamda "yeni konformizm" ile uyumlu hale gelmektedir. Ona göre spiritüellik arayışında olan "yeni konformist" bireyler "yoga yapıp kendine değer verilmesini” arzulamakta, günah ya da bağışlanmayı değil, "binlerce yıl önce yazıllmış hikâyelerle kısitlama değil hayat öykülerini yenileme özgürlüğ̈̈” istemektedirler (s. 65). Taburoğlu da söz konusu spiritüel akımlar içerisinde her bireyin kendi kişisel metafiziğini ve ikonlarını yaratabileceği çoğul bir kutsallık alanının açıldığını söyler.

"Yaşam biçimleri" bu kutsallığın deneyimlendiği alanlara taşınırken kutsallık da bireyselliği besleyen bir yapıya kavuşmaktadır. Çünkü kendi farklılı̆̆ına, özne olma hallerine fazlaca sahip çıkanların otoriter bir dini yapı içinde, kendi bireyliklerinin kuşatıldığı bir alan içinde rahat etmeleri zorlaşmaktadır (Taburoğlu, 2008, s. 223). Dolayısıyla "bireyselleşmiş toplum"da "azla yetinirliği, kişinin kendisine sınırlar koymasını, keyfini kısmasını ögütleyen teolojiler, kozmolojiler" bu yaşam biçimi içerisine dâhil olamamakta, çünkü "modernliğin varlıkbilimi, ontolojisi, böyle sebatkâr bir tavrı” dışlamaktadır (Taburoğlu, 2008, s. 11).

Böylece gündelik yaşamı estetize etme, hayatı bir sanat eseri olarak yapılandırma eğilimlerinin (Featherstone, 2013, s. 124) postmodern versiyonlarında, kutsal anlam ve pratikler de yaşam tarzı inşa etmek için kullanılabilmektedir. Yeni gerçeklik ve deneyim alanlarının, sınırları kaldıran bir yaşam tarzının inşasında bedensel ve ruhsal gelişim seminerleri, "spiritüel ufuk açıcı dersler" iş başındadır (Funk, 2013, s. 123). Postmodern bireyin hem bedensel hem de ruhsal açıdan "kendini iyileştirme çabaları" bağlamında değerlendirilebilecek bu pratikler, belli bir endüstri ve pazar yaratmakta, bu endüstri kendi yol göstericiliğini de günden güne pekiştirmektedir (Funk, 2013, s. 212-6). Üstelik söz konusu spiritüel pratikler, örneğin terapi grupları bireye bir topluluk içerisine dahil olma imkanı 
sunarken, özgün bir benlik performansı geliştirme yönündeki eğilimlerini de doyurmaktadır (Funk, 2013, s. 215).

Söz konusu manevi pratik ve anlamlar postmodern bir yaratıcılık ve sınırsızlaştırma altında yapı sökümüne de uğrayabilmekte, yeni bir anlayış ve bireysellik etrafında yorumlanabilmektedir. Funk buna "yamalı bohça maneviyatçllı̆ı" der. Bu kavramsallaştırma, farklı dinsel ve din benzeri öğelerin bir araya getirildiği; gerçek dışı, mistik, gizemli tecrübelerle "yamalı bohça kimlik"lerin, "çok yüzlü benliklerin" bir arada var olduğu postmodern bir varoluşa işaret etmektedir. "Yamalı bohça bir kimlik", "yamalı bohça maneviyatçılığın" ardındaki temel dinamiklerden biridir (Funk, 2013, s. 86 ve 217).

Kendi dinselliğinin ve maneviyatının yaratıcısı olmak ister o. Dinle bir ilgisi olmadığ söylenemez, tam tersine gündelik ve kaçınılmaz dünyayı, verili gerçekliği ve kendiliğini daha yüksek bir gerçekliğe ve manevi bir kendiliğe taşıyarak aşkınlaştırmak istemektedir aktif ben-odaklı karakter. Özellikle yaşama sanatı söz konusu olduğunda aktif ben-odaklı karakterin sınırsızlık arzusu özel bir önem kazanmaktadır. Doğrudanlığı deneyimlemek, anın tadını çıkarmak, burada ve şimdiyi yaşamak, zamanın ve mekânın sınırlarını dinsel ve spiritüel egzersizlerle, pratiklerle aşmak istemektedir. Son yıllarda ezoterizme, Zen Budizmi ve Sufizme duyulan ilginin artmasında postmodern insanın "mistik" şeylere duyduğu hayranlığın da payı vardır (Funk, 2013, s. 73).

Tarihteki mitlerin, spiritüel sembol ve mitolojilerin kültürel tüketimi, geçmişin öznel yorumlar etrafında yeniden kuruluşuna, icat edilmesine de gönderme yapar, bu anlamda söz konusu tüketim bir kültürel yeniden üretim sürecini de imlemektedir. Geçmiş zamanlara ait spiritüel imgeler, efsaneler, semboller öznel bir yorum etrafında inşa edilirken, öznenin bireyselliğini besleyecek bir şekilde yeniden yapılandırılabilir. Geçmişe ait kültürlerin eklektik tüketimi öznel mitler inşa etmek için potansiyel bir alan haline gelebilmektedir (Possamai, 2002, s. 202-203). Kültürel tüketim "anlamların dönüştürüldüğü de bir süreç olarak" (Possamai, 2002 s. 203) maneviyat alanına taşındığında benliğin inşası için "egzotik ve "cezbedici" bir araç olarak da belirebilmektedir. "Yaşam tarzını, benliğini, entisitesini kurmak, kendisine dâhil olabileceği bir kabile seçmek isteyenlere, etnik simgeler dünyasını, Uzak Doğulu, Hintli kültürleri, mistik öğretileri erişebilir kılan” (Taburoğlu, 2011, s. 174) bu süreç bireyin fantezi ve ihtiyaçlarını giderecek biçimde yeniden yorumlanabilmekte, eğilip bükülebilmektedir.

Kendi kişisel mitolojisini yaratacak olan birey, manevi anlam boşluklarını dolduracak yeni kaynaklar, ruhsal içerikler ararken modernliğin, geç modernliğin yarattığı belirsizlikle de baş etmeye çalışır. Funk’a göre popüler spiritüel ve dinsel pratikler bireyin modern sonrası dönemde radikalleşen anlamsızlık, yönsüzlük gibi eğilimlerini giderebilecek bir nesne ihtiyacını da karşılık gelir. "Yoğunlaşma, meditasyon ve gevşeme egzersizleri, otojen eğitim, yoga, ve t’ai chi" gibi dinsel ve yarı dinsel pratikler bireyin yaşam sanatı inşa etmesinde, kendini yeniden yapılandırabilmesinde ve yönünü bulabilmesinde, postmodern bir yeniden yorumlama, keyfi bir değiş tokuş sürecine de dahil olabilmektedir (Funk, 2013, s. 217). "Yönünü yitirmiş" bireyin telkine açıklı̆ğ daha güçlü ve kurumsal telkin mekanizmalarını da devreye sokmaktadır (Funk, 2013, s. 51). Bunlar bireyin kendisini yeniden yaratmasına ve daha iyi bir biçimde sunmasına yönelik pratikler sunan çeşitli 
aracılardır. Örnek olarak "kişilik çalıştırıcıları", kişilik kurucuları" ya da spiritüel danışmanlık gibi mekanizmalar gösterilebilir (Funk, 2013, s. 34-35). ${ }^{7}$

Bauman’n her yana sızmış bir belirsizlik evreninde, "postmodern insanın" simyacı arama eğilimi olarak tanımladığı sürece denk düşmektedir bu pratikler. Zira "postmodernlik kimlik sorunu uzmanlarının, kişilik hekimlerinin, evlilik danışmanlarının, kendine güvenmenin yolları türünden kitapların yazarlarının çağıdır. Postmodernlik, 'danışma patlaması' çağıdır’' (Bauman, 2013, s. 265). Ona göre "danışma patlamasının ürünleri" bedenin duyum potansiyelini arttırma, iç yoğunlaşma, egzersiz, kişisel büyüme gibi vaatlerle işlevselleşen "kendini geliştirme" sektörüdür. Fakat bunlar dini piyasanın tüketim nesneleri gibi sadece tüketici seçimlere hizmet veren bir sektör değildir. Daha çok seçici deneyim arayan, duyum ve deneyim peşindeki bir tüketim davranışını ifade eder. Birey, spiritüel tekniklerle kendisini "aşmanın", tedavi etmenin, "akışa" teslim olmanın yöntemlerini ararken en batıni ve egzotik maneviyat içeriklerini de bir teknik, anlam öbeği ve bilgelik tarzı olarak sahiplenir, tüketir (Bauman, 2013, s. 270).

Söz konusu spiritüel tüketim, Bauman’’n (2013) "zirve deneyimler" olarak tanımladığı postmodern tüketim tarzıyla da birlikte düşünülebilir. "Zirve deneyimler” in dinsel versiyonu kişiyi bir çile hayatına razı edebilecek içeriğe sahipken, bunun postmodern versiyonu olan "tüketimcilik aristokrasinin öncü ve peygamberleri" ya da "danışma patlamasının ürünleri doyuma ulaşmayan, sürekli deneyim peşinde koşan, daha rafine ürünler tüketen ve bunu daha sofistike tarzda tüketen birey tipi önermektedir. Dolayısıyla tüketim kültürü içerisinde maneviyat biçim ve içerikleri bir "duyum toplama ve duyum arttırma" aracı olarak yeniden biçimlenebilmektedir (s. 269).

Anlam kaybına uğrayan, dünyevileşen yaşam biçimlerini zenginleştirecek ve yeniden büyüleyecek kaynaklar, tüketim kanallarında arzu, tatmin, haz biçimleri olarak hazır durmaktadır (Chaney'den akt. Taburoğlu, 2011, s. 155-156). Bauman’ın (2013) postmodern bir tüketim kültürü içerisinde "haz arayıcı ya da duyum toplayıcı rolünün kanatları altında toplumsal olarak" da biçimlendiğini söylediği bireyler açısından (s. 266) maneviyat, aşkınlık vaat eden bir deneyim alanı olarak kendi bağlamı, felsefesi ve tarihselliğinden de uzaklaşabilmektedir.

Söz gelimi bir Hint fakirinin kendi fakirliğiyle ve kendisini çevreleyen kalabalıkla uzlaşabilmek için uyguladığı meditasyon teknikleri, bu öğretiler içerisinde başka işlevler için kullanılır. Çoğunlukla da karşıt bir amaç için, bolluğun, zenginliğin yarattığı toplumsal sorunları telafi etmek için başvurulur. Meditasyon, onu uygulayan Hintli için bir içsel mahremiyet alanı yaratma, dışsal uyaranları yok etme çabasıyken, kişisel gelişim öğretilerini uygulayanlar

$7 \mathrm{Bu}$ danışmanlık mekanizmalarını Bourdieu’nun "yeni kültür aracıları” kavramıyla da birlikte değerlendirebiliriz. "Yeni kültür aracıları" olarak adlandırılan kesime medya ve iletişim alanında çalışanların yanında danışmanlar ve terapistler de dâhil olmakta, dışavurumsal bir yaşam tarzı inşasında, hayata bir üslup kazandırma, kimlik, tecrübeler ve "ruhsal zenginlik göstergeleri" inşa etme konusunda çağdaş kültürde "yeni entelektüeller olarak işlev görmektedir. Söz konusu kültür aracıları popüler kültür ve yüksek kültür arasında olduğu varsayılan simgesel ve hiyerarşik ayrımların aşındırılmasına da yardımcı olmaktadır. Entelektüel ve sanatsal yaşam tarzları kurmaya yardımcı olan "yeni entelektüeller" postmodernizme içkin eğilim ve talepleri karşılama ve bu talepleri yaratma konusunda çağdaş kültürde önemli toplumsal özneler olarak yer almaktadır (Featherstone, 2013, s. 91-92). "Sürekli öğreniyor ve kendini zenginleştiriyor olma arzusu, her zaman yeni değerler ve sözcükler peşinde koşma arzusu”nun uzun bir tarihi olsa da yeni orta sınıf üyeleri olarak "kültür aracıları" bunları daha geniş bir kesime yaymaktadır (s. 97). 
tarafından, dünyanın ve yaşamın zenginliğine daha iyi katılabilmek için başvurulan bir etkinliktir. [...] Çinli’nin, Hintli’nin ya da mistik bir öğreti etrafında toplanan her topluluğun yaşam tekniklerinin uzanımları olan uygulamalar, geç-kapitalizmin, endüstri-sonrasının huzursuz sakinleri tarafindan, biraz da sorumsuzca, birer hazır-yapım zihinsel ve bedensel gelişim tekniği gibi talan edilir (Taburoğlu, 2011, s. 171-2).

\section{Sonuç Yerine}

Bauman’ın sabitlik yerine esneklik, kapalılık yerine açıklık ve akışkanlık arayan kişiler olarak metaforlaştırdığı "duyum toplayıcılar" ya da "deneyim koleksiyoncuları" (Bauman, 2013, s. 48) açısından spiritüel felsefeler, postmodern bir farklılaşma, bireyselleşme ve yaşam tarzı inşa etme taleplerine karşılık veren "egzotik" ve "otantik” bir alan olarak da değerlendirilebilmektedir tüketim kültürü içerisinde. Bauman’a göre (2013) "nefsin duvarlarını yıkma ve tam aşkınlık deneyimi, postmodern kültür tarafından her bireyin ulaşabileceği bir şey” olarak konumlandırılırken, insan potansiyelinin sonsuzluğunu yücelten bir "nefsi okşama sanatı" da dönüşmektedir (s. 268). Böylesi bir eğilim içerisinde spiritüellik bir boş zaman etkinliği haline gelebilmekte, öte yandan bir metalaşma sürecine de dâhil olmaktadır. Postmodern yaşama pratiklerinin karşısında geleneksel din anlayışlarının, "büyük dini anlatıların” doktriner direncinin kırılması ile de anlaşılabilecek bu süreç, postmodern "yaşam sanatını” kurabilmek açısından yeni imkânlar ve deneyimler arayışında olan bireye, aşkın bir kendilik alanı da sunmaktadır.

\section{Kaynakça}

Adorno, T. W. ve Horkheimer, M. (2014). Aydınlanmanın diyalektiği: felsefi fragmanlar. (Çev. N. Ülner ve E. Ö. Karadoğan) İstanbul: Kabalc1.

Adorno, T. W. (2016). Kültür endüstrisi kültür yönetimi. A.Artun (Haz.), (Çev. N. Ülner), İstanbul: İletişim Yay. Atay, T. (2004). Din hayattan çıkar: antropolojik denemeler. İstanbul: İletişim Yay.

Aydemir, F. (2017). Popüler kültürde mistik motifler: bir anlatı, tüketim ve gösteri alanı olarak tasavvuf. Yayımlanmamış Yüksek Lisans Tezi. Ankara: Ankara Üniversitesi Sosyal Bilimler Enstitüsü.

Aydemir, F. (2018), New age dini söyleminde narsistik bilgelik: İndigo dergisi üzerine bir inceleme, Özet Bildiri, Yayın Yeri: International CICMS Conference.

Baudrillard, J. (2016). Tüketim toplumu. H. Deliceçaylı ve F. Keskin(Çev.), İstanbul: Ayrıntı.

Bauman, Z. (1999). Çalışma tüketicilik ve yeni yoksullar. Ü. Öktem (Çev.), İstanbul: Sarmal.

Bauman, Z. (2003). Yasa koyucular ile yorumcular. E. Yılmaz (Çev.), İstanbul: Ayrıntı.

Bauman, Z. (2005). Bireyselleşmiş toplum. Y. Alogan (Çev.), İstanbul: Ayrıntı.

Bauman, Z. (2011a). Modernite, postmodernite ve etik, Cantell Pedersen ile Söyleşi, Doğu Batı Düşünce Dergisi, 3.baskı, A. Yıldız (Çev.). Ankara: Doğu Batı Yayınları, (19), s. 53-63.

Bauman, Z. (2011b). Yaşama sanatı. A. Sarı (Çev.). İstanbul: Versus Kitap Yay.

Bauman, Z. (2012). Küreselleşme: toplumsal sonuçları. A. Yılmaz (Çev.). İstanbul: Ayrıntı.

Bauman Z. (2013). Postmodernizm ve hoşnutsuzlukları. 2.baskı, İ. Türkmen (Çev.). İstanbul: Ayrıntı Yay.

Bauman, Z ve D, Lyon. (2013). Akışkan gözetim. E. Yılmaz (Çev.). İstanbul: Ayrıntı.

Berman, M. (2006). Katı olan her şey buharlaşıyor. Ü. Altuğ ve B. Peker (Çev.). İstanbul: İletişim. 
Best, S., ve Kellner, D. (2016). Postmodern teori: eleştirel soruşturmalar. 3.basım, M. Küçük (Çev.) İstanbul: Ayrintı.

Bocock, R. (1997). Tüketim. İ. Kutluk. (Çev.). Ankara: Dost Kitabevi Yayınları.

Carrette, J. ve King, R. (2005). Selling spirituality: the silent takeover of religion. New York; Londra: Routledge.

Douglas, M. ve Isherwood, B. (1999). Tüketimin antropolojisi. E. A. Aytekin (Çev.). Ankara: Dost Kitapevi Yayınları.

Einstein, M. (2008). Brands of faith: marketing religion in a commercial age, London; New York: Routledge.

Featherstone, M. (2013). Postmodernizm ve tüketim kültürü. M. Küçük (Çev.). 3. Baskı, İstanbul: Ayrıntı.

Firat, A. F. ve Schultz, C., S. (2001). II. Preliminary metric investigations into the nature of the postmodern consumer, Marketing Letters. 12.2.

Frisby, D. (2012). Modernlik fragmanlar: Simmel, Kracauer ve Benjamin'in eserlerinde modernlik teorileri, A. Terzi (Çev.). İstanbul: Metis.

Funk, R. (2013). Ben ve biz: postmodern insanın psikanalizi. Ç. Tanyeri (Çev.). 2.baskı, İstanbul: Yapı Kredi Yay.

Giddens, A. (2010). Modernite ve bireysel-kimlik: geç modern çağda benlik ve toplum. Ü. Taltıcan (Çev.). İstanbul: Say Yay.

Giddens, A. (2012). Modernliğin sonuçları. E. Kuşdil (Çev.). İstanbul: Ayrıntı.

Hall, S. (1195). Yeni zamanların anlamı, S. Hall ve M. Jacques (Ed.). Yeni Zamanlar içinde, (s. 105-118). İstanbul: Ayrintı.

Harvey, D. (1997). Postmodernliğin durumu. İstanbul: Metis Yay.

Jameson F. (2005). Kültürel dönemeç. K. İnal (Çev.). Ankara: Dost.

Kellner, D. (2000). Toplumsal teori olarak postmodernizm: bazı meydan okumalar ve sorunlar, Modernite Versus Postmodernite içinde, 3.baskı, (Haz.), M. Küçük, Ankara: Vadi, s. 367-404.

Kellner, D. (2004). Popüler kültür ve postmodern kimliklerin inşası, Doğu Batı Dergisi, G. Seçkin, (Çev.). 4(15), s. 187-219.

Kozanoğlu, C. (1997). İnternet dolunay cemaat. 3.baskı, İstanbul: İletişim.

Köse, A. (2011). Milenyum tarikatları: Batı'da yeni dini akımlar. İstanbul: Timaş Yay.

Lasch, C. (2006). Narsisizm kültürü. Öztürk ve Ü. H. Yolsal (Çev.). Ankara: Bilim ve Sanat Yay.

Mirza, G. (2014). Yeni dinselleşme eğilimleri ve maneviyat arayışları, Yayımlanmamış Doktora Tezi, Antropoloji Anabilim Dalı, Ankara: Hacettepe Üniversitesi Sosyal Bilimler Enstitüsü.

Murray, R. (1995). Fordizm ve post-fordizm, S. Hall ve M. Jacques, (Ed.). Yeni Zamanlar içinde (s. 46-57), İstanbul: Ayrinti.

Niedzvieck, H. (2011). Ben özelim: bireysellik nasıl yeni konformizm haline geldi. Erduman (Çev.). İstanbul: Ayrintı.

Odabaşı, Y. (2004). Postmodern pazarlama. İstanbul: MediaCat

Paker, K. O. (2011). Postmodern bilgelik: yeni çağ söyleminde kişisel gelişim ve ruhsal alıştırmalar, Psikoloji Çalışmaları Dergisi, (31), s. 61-98.

Possamai, A. (2002). Cultural consumption of history and popular culture in alternative spiritualities, Journal of consumer culture. Erişim Tarihi, 15.05.2019 tarihinde http://ezproxy.uws.edu.au/ login?url=http://www-mi2.csa.com/ids70/view_record.php?id=1\&recnum=2\&log=from_ toc\&SID =a0089000fba60f07fc362a5b6736194e adresinden edinilmiştir.

Sennett, R. (1996). Kamusal insanın çöküşü. S. Durak ve A. Yılmaz (Çev.). İstanbul: Ayrıntı.

Sennet, R. (2002). Karakter aşınması: yeni kapitalizmde işin kişilik üzerine etkileri. Çev., B. Yıldırım, İstanbul: Ayrint1. 
Sennet, R. (2015). Yeni kapitalizm kültürü. A. Onacak (Çev.). İstanbul: Ayrıntı.

Simmel, G. (2006). Modern kültürde çatışma. T. Bora ve N. Kalaycı ve E. Gen (Çev.). İstanbul: İletişim.

Slater, D. R. (1997). Consumer culture and modernity. Cambridge: Polity Press.

Swartz, D. (2015). Kültür ve iktidar: Pierre Bourdieu’nun sosyolojisi. E. Gen (Çev.). İstanbul: İletişim.

Taburoğlu, Ö. (2008). Dünyevi ve kutsal: modernlerin maneviyat arayışları. İstanbul: Metis.

Taburoğlu, Ö. (2011). Kent efsaneleri: zamanımızın batıl inançları ve takıntıları, Ankara: Doğu Batı.

Urry, J. (1995). Örgütlü kapitalizmin sonu, S. Hall ve M. Jacques (Ed.). Yeni Zamanlar içinde, (s.95-98), İstanbul: Ayrinti.

Wernick, A. (1996). Promosyon kültürü: reklâm, ideoloji ve sembolik anlatım. O. Akınay (Çev.). Ankara: Bilim ve Sanat.

Woodward, I. (2016). Maddi kültürü anlamak, F. B. Aydar (Çev.). İstanbul: İş Bankası ve Kültür Yay. 


\section{A Metatheoretical and Conceptual Discussion on Postmodern Consumption Culture and Forms of Sacredness: Spirituality as Experience, Lifestyle and Field of Individuality}

Feride AYDEMİ* ${ }^{*}$

Consumption is both a material as well as a symbolic process (Featherstone, 2013, pp. 210-211), and as a social and cultural process involving signs and symbols (Bocock, 1997, p. 13), it creates both new forms of discourse, style and subjectivity and as well as new forms of articulation by spreading to various areas of cultural and social life. Consumption as a central phenomenon in terms of exhibiting personality, transforming styles and tastes into narrative code (Bauman and Lyon, 2013, p. 120), both in terms of social identities and social distinctions, the endless desires rather than satisfaction, excitement rather than finding (Bauman, 2012, p. 87), it increases the individual's fluidity and ability to move in different channels. In the consumption culture, not only objects are released in an exchange partnership; ideologies, ideas and belief systems are also involved in this process (Baudrillard, 2016, p. 111).

Especially after the 1970s in the world and in Turkey, religious and spiritual practice return as political cultural and social reaction. And they are moving to the periphery from the center of popular culture, media and public sphere. In recent years, religious practices and discourses that can be gathered under the New Age movements, have created some articulation forms in various channels of consumer culture. This process includes an interaction between religious and profane which the distinctions become faded, and the commodification of the sacred in consumption channels. Spiritual-esoteric meanings and practices appear in various channels of consumer culturesuch as yoga, meditation, mysticism, sufism, mass media, books and magazines sector, personal development seminars and trainings, consulting services, tourism, such as taking place in a wide spectrum of consumption. The objects of spiritual consumption that are watching are also increasing with each passing day (Aydemir, 2017). On the other hand, the way in which spiritual meanings are constructed and discursively established in various media channels may have a similarity to the system of values of narcissism culture in this sense, which constructs an exalted image of subjectivity (Aydemir, 2018).

Res. Asst., Ankara University, Public Relations and Publicity Department, Ankara, Turkey, E-mail: ferideguner59@gmail.com, ORCID ID: 0000-0002-0787-243X 
Characterized by a distinctive, pluralist and eclectic structure rather than a monolithic world, idea of the New Age reveals radical examples of individualization of faith as a postmodern repertoire (Mirza, 2014, p. 51; Paker, 2011, p.70, Niedzviecki, 2011, 82, Kozanoglu, 1997, pp. 23-4). First of all, this trend exhibits an eclectic structure with religious and non-religious elements. Its main areas are: Astrology, dream, alchemy, herbal treatment, magic, mysticism, alternative medicine, shamanism, Christian symbolism, Feng Shu, Taoism, Zen, Buddhism, Mysticism, Sufism, meditation, yoga and so on. (from Bruce Köse, 2011, p. 134). These practices offer ambiguity rather than determinism, diversity rather than uniqueness, differentiation instead of simplification (cf. Possamai, 2002, p. 208), in this sense, they can produce discourses and practices appropriate to the postmodern character of consumer culture by presenting a postmodern existence.

This study aims to conduct a conceptual and theoretical discussion of the dynamics and current aspects of this process. The study aims to continue this discussion on three levels: a) Holiness as an area of individuality; b) cultural consumption and reproduction of spiritual symbols and meanings; c) The place of sacred, spiritual meaning, symbols and practices in the consumer market as a commodity-object. This paper argues that in contemporary consumer culture, spiritual meanings and contents can become popular spiritual forms of individual mythology, of creating a distinctive style and that the sacred can be reinterpreted around a new look and subjective interpretation that corresponds to today's quests and fantasies. The postmodern forms of holiness that offer the ways and methods of feeling "perfect", and of a physical and spiritual "wisdom" add a spiritual dimension to an individualized narrative of a lifestyle, and on the other hand can be objectified in the consumer markets through a commodity circulation.

In postmodern-late modern culture, consumption is also experienced as a process of selfrealization, reconstruction and creation (Funk, 2013, p. 242-3) and for some individuals this process can be carried to the field of spirituality. This is because the radicalization of the dynamics of individualization in the postmodern-late modern haunt deepens the focus on the self, and this process can increase the contact with the spiritual. Because in a consumer culture in which "personalization, being and being found identity (Baudrillard, 2016, pp. 102-103) is exalted as much as possible, spiritual meanings and contents can become popular spiritual forms of establishing an individual mythology, creating a distinctive style and style.

The study considers various conceptualizations of consumption (Douglas and Isherwood, 1999; Bocock, 1997), but the conceptualization of consumption is based on the perspective of "material cultural studies (Woodward, 2016). Such an approach provides the opportunity to overcome the purely materialistic, economist reductionist conception of consumption, and on the other hand, it also distances from the understanding that reduces the consumption process to a completely "false consciousness" issue, or to the ideological domination tool of a ruling culture.

While the study aims to conduct a theoretical and conceptual discussion, it first focuses on the issue of identity and individuality in the postmodern-late modern era. In this section, the relationship between modern and postmodern is tried to be evaluated in terms of totality and dialectically, not within the framework of breaks. In this study, Berman's (2006) and Simmel's (2006) views on modern 
culture and postmodern ideas (Best and Kellner, 2016; Giddens, 2010; Harvey, 1997; Jameson, 2005;) were fed. Also the supposed transformations of identity in the fluidity (Bauman, 2005, 2011a and 2011b; Firat and Schultz, 2001; Funk, 2013; Giddens, 2010; Hall, 1995; Kellner, 2004; Lasch, 2006; Odabaş1, 2004; Sennet, 1996 and 2002; Urry, 1995) and the reflection forms of the process on consumption culture and the views of mediation with the issue of individuality based on the conceptualizations of the study, a discussion was conducted around the problematic of the study. (Bauman, 2012; Featherstone, 2013, Murray, 1995; Slater, 1997).

The consensus and articulations between the sacred and secular within the late modern, postmodern consumer culture are able to transform the sacred into a resource that carries economic "rationality", into a capital that works in favor of worldly (Taburoğlu, 2008, 2011; Carrette and King, 2005; Einstein, 2008) and symbolic and cultural consumption and reproduction of meanings.

Consumption and leisure practices that allow the production of self are also carried to the religious sphere for some. The cultural openness to the exotic and inconvenient in the postmodern consumer culture (Funk, 2013: pp. 68-70) carries the tendencies of self-construction and individualism to the field of religious-semi-religious meaning and practices, and the experiences of being in the consumption culture also change the relationship forms and the acts of consumption established with spiritual meaning and practices. The process also includes the commodification of these sacred forms in the channels of consumption. This process, which can be understood by breaking the doctrinal resistance of traditional religious understandings and "great religious narratives" in the face of postmodern life practices, also offers a transcendental space of self to the person who is searching for new opportunities and experiences in order to establish postmodern art of life.

Keywords: Postmodernity, Consumption Culture, Individuality, Postmodern Spiritualities, Spirituality Consumption. 